\title{
Evaluation of Physical Characteristics of Typical Maize Seeds in a Cold Area of North China Based on Principal Component Analysis
}

\author{
Han Tang ${ }^{1,2}$, Changsu Xu ${ }^{1}$, Yeming Jiang ${ }^{1} \mathbb{D}$, Jinwu Wang ${ }^{1, *} \mathbb{C}$, Zhenhua Wang ${ }^{3, *}$ and Liquan Tian ${ }^{2,4, *}$ \\ 1 College of Engineering, Northeast Agricultural University, Harbin 150030, China; \\ tanghan@neau.edu.cn (H.T.); ChangsuXu@neau.edu.cn (C.X.); jiangyeming951120@163.com (Y.J.) \\ 2 Key Laboratory of Crop Harvesting Equipment Technology of Zhejiang Province, Jinhua 321007, China \\ 3 College of Agriculture, Northeast Agricultural University, Harbin 150030, China \\ 4 School of Mechanical and Electrical Engineering, Jinhua Polytechnic, Jinhua 321007, China \\ * Correspondence: jinwuw@neau.edu.cn (J.W.); Zhenhuawang_2006@163.com (Z.W.); \\ tlqbuct@foxmail.com (L.T.); Tel.: +86-0451-55190950 (J.W. \& Z.W. \& L.T.)
}

check for updates

Citation: Tang, H.; Xu, C.; Jiang, Y.; Wang, J.; Wang, Z.; Tian, L.

Evaluation of Physical Characteristics of Typical Maize Seeds in a Cold Area of North China Based on Principal Component Analysis. Processes 2021, 9, 1167. https://doi.org/10.3390/ pr9071167

Academic Editors: Yonghui Li and Shawn/Xiaorong Wu

Received: 2 June 2021

Accepted: 2 July 2021

Published: 5 July 2021

Publisher's Note: MDPI stays neutral with regard to jurisdictional claims in published maps and institutional affiliations.

Copyright: (c) 2021 by the authors. Licensee MDPI, Basel, Switzerland. This article is an open access article distributed under the terms and conditions of the Creative Commons Attribution (CC BY) license (https:/ / creativecommons.org/licenses/by/ $4.0 /)$.

\begin{abstract}
The physical properties of maize seeds are closely related to food processing and production. To study and evaluate the characteristics of maize seeds, typical maize seeds in a cold region of North China were used as test varieties. A variety of agricultural material test benches were built to measure the maize seeds' physical parameters, such as thousand-grain weight, moisture content, triaxial arithmetic mean particle size, coefficient of static friction, coefficient of rolling friction, angle of natural repose, coefficient of restitution, and stiffness coefficient. Principal component and cluster comprehensive analyses were used to simplify the characteristic parameter index used to judge the comprehensive score of maize seeds. The results showed that there were significant differences in the main physical characteristics parameters of the typical maize varieties in this cold area, and there were different degrees of correlation among the physical characteristics. Principal component analysis was used to extract the first three principal component factors, whose cumulative contribution rate was over $80 \%$, representing most of the information of the original eight physical characteristic parameters, and had good representativeness and objectivity. According to the test results, the classification standard of the evaluation of the physical characteristics of 15 kinds of maize seeds were determined, and appropriate evaluations were conducted. The 15 kinds of maize seeds were clustered into four groups by cluster analysis, and the physical characteristics of each groups were different. This study provides a new idea for the evaluation and analysis of the physical properties of agricultural materials, and provides a new method for the screening and classification of food processing raw materials.
\end{abstract}

Keywords: northern cold area; maize seeds; physical characteristics; principal component analysis; cluster comprehensive analysis

\section{Introduction}

Maize is the main grain crop in China, contributing grain and feed to the economy. Maize is also an important raw material for food processing. Effective evaluation and screening of raw materials is important to enhance the nutrition and taste of raw food [1-3]. The processing parameters of drying, cooking, and baking maize with different physical properties also differ, and the evaluation of physical properties of maize seeds is also crucial for guiding food processing [4-6].

Maize can be made into many kinds of food and additives after deep or primary processing. Deep processing can extract crude amino acid and starch from corn seeds to form liquor or yeast [7]. The primary processed products are widely used in daily life, and can be made into corn flour or corn paste for flushing [8]. The comminution degree of 
maize in primary processing is closely related to its physical properties. The main factors influencing the comminution degree are the moisture content, particle surface area, friction characteristics, and mechanical properties of maize grain. Kyttä et al. [9] found that the friction coefficient is an important parameter reflecting the influence of raw materials on the wear of the pressed film. The higher the friction coefficient of the raw materials, the lower the service life of the pressed film. Córdova-Noboa et al. [10] found that physical properties can affect the flow of maize grain in food processing machinery, and then affect the binding process, with effects between different grains. The research on the physical characteristics of maize grain has important guiding value for the development and production of related food processing machinery and equipment.

The study of the characteristics of agricultural materials is a basic discipline formed in conjunction with the development of agricultural engineering [11]. The physical parameters of maize seed, as a typical agricultural material, mainly include basic characteristic parameters, friction characteristic parameters, mechanical characteristic parameters, and electrical characteristic parameters. [12]. Through study of maize seeds' physical characteristics, varieties with similar physical characteristics can be comprehensively evaluated and selected for statistical analysis, which can be combined with clustering methods to extract a reasonable range of physical parameters. Scholars have researched the determination of the physical characteristics parameters of maize seeds [13-15]. Zhang et al. [16] proposed a method for calibrating the interspecies contact parameters of the maize seed particle model based on the discrete element method, which provided effective boundary conditions for its virtual simulation. Wang et al. [17] proposed a method for measuring the rolling friction coefficient and collision recovery coefficient of maize seeds based on the energy conservation law and the principle of specular reflection, which provided a new method for obtaining the mechanical parameters of granular agricultural materials. However, the corresponding planting varieties that are suitable in different areas of China are different, and their physical characteristics may also be significantly different. There are few reports on the measurement of physical parameters of maize varieties suitable for planting in the cold areas of Northern China. The literature data and experience do not fully provide the data needed for machine development.

At present, the evaluation of the parameters of agricultural materials is mainly based on conventional appearance quality and sensory evaluations, chemical composition evaluation, and single-factor evaluation [18,19]. Appearance quality and sensory evaluations are vulnerable to subjective influence, so have poor generalization and application value. Single-factor evaluation is vulnerable to the influence of single indexes, which reduces the overall evaluation accuracy, so it is impossible to conduct a systematic and comprehensive quantitative evaluation. Therefore, objective, scientific, and effective methods are needed for this type of evaluation [20]. Chemical composition evaluation methods are mainly achieved through weight analysis or bulk density analysis to extract products from samples. Related research mainly focused on the determination of polysaccharide, ash, crude fat, and protein contents in maize, wheat, rice, and other staple crops; pineapple; apple; and other baked fruits and vegetables [21,22]. Based on a chemical composition evaluation method, Salvador-Reyes et al. [23] studied different varieties of maize from different areas and found that there was no significant differences in ash, crude fat, and protein contents. Principal component analysis reduces the loss of information from raw data, simplifies the data structure, and avoids subjective randomness. It is widely used in comprehensive evaluation in various fields. Yang et al. [24] classified the characteristics of various potato varieties and their processing suitability based on the principal component analysis, and provided a reference for the division of potato processing uses. Mu et al. [25] used principal component analysis and cluster analysis to evaluate and analyze multiple agronomic traits of multiple peanut germplasm resources, which provided a reference for the selection of excellent peanut varieties and multi-functional applications. Lu, Dai, Luo, and Liu [26-29] measured and evaluated the physical characteristics of rice, soil, earthworm dejecta substrate, and potato, respectively. The above research mainly classified and evaluated some 
kinds of crops, but the principal component analysis and the evaluation of the physical characteristics of maize, especially the maize in cold areas of North China, have not been reported.

Given this background, we used typical maize varieties in the cold areas of Northern China to determine their thousand-grain weight, moisture content, triaxial arithmetic mean particle size, coefficient of static friction, coefficient of rolling friction, angle of natural repose, coefficient of restitution, and stiffness coefficient. Principal component analysis was used to simplify the parameter index, and the comprehensive score of the various maize varieties was judged in order to construct a scientific and reasonable evaluation system. Our findings provide a new idea for the evaluation and analysis of the physical properties of agricultural materials, and provides a new method for the screening and classification of raw food processing materials.

\section{Materials and Methods}

\subsection{Principal Component Analysis of Physical Maize Seed Characteristics}

The basic idea for the evaluation of the physical characteristics of maize seeds using principal component analysis mainly involved constructing a linear combination of the characteristic physical parameters and calculating new variables that are irrelevant and contain the information of the original variables. Through the new variables that were determined to replace the complex original variables to analyze and solve the problem, complex problems can be simplified [30]. The steps are were follows: (1) The indexes needed to evaluate the physical properties of maize seeds were determined, including thousand-seed weight, moisture content, triaxial arithmetic mean particle size, natural angle of repose, static friction coefficient, rolling friction coefficient, impact recovery coefficient, and stiffness coefficient. (2) A bench test of material characteristics was conducted to obtain the test data of physical parameters. (3) We conducted correlation analysis and a preliminary evaluation of the characteristic physical parameters. (4) We conducted principal component analysis of the characteristic physical parameters. (5) Through the cumulative index contribution rate of the principal components and the bottom lithotripsy map, the number of principal components was selected to achieve index dimensionality reduction. (6) The test data the physical parameters were substituted into the principal component formula to obtain a principal component score, and then the contribution rate of each principal component was used as the weight value to produce a comprehensive score, and then we conducted the final quantitative evaluation.

In step 2, during the bench test of material characteristics, the test data were standardized.

$$
x_{i}^{\prime}=\frac{x_{i}-\bar{x}_{i}}{\sqrt{\frac{1}{n-1}} \sum_{i=1}^{n}\left(x_{i}-\bar{x}_{i}\right)^{2}}
$$

In step 3, correlation analysis was conducted, and the correlation coefficient matrix $R$ of each index was solved. The Pearson product moment formula was adopted for the correlation coefficient between indexes $x$ and $y$.

$$
r_{x y}=\frac{\sum_{i=1}^{n}\left(x_{i}-\bar{x}\right)\left(y_{i}-\bar{y}\right)}{\sqrt{\sum_{i=1}^{n}\left(x_{i}-\bar{x}\right)^{2} \sum_{i=1}^{n}\left(y_{i}-\bar{y}\right)^{2}}}
$$

where $\bar{x}$ and $\bar{y}$ are the mean values of indexes $x$ and $y$, respectively; and $x_{i}$ and $y_{i}$ are the $i$ th measured values of indexes $x$ and $y$, respectively.

The characteristics values of the correlation coefficient matrix $R$ and the corresponding normalized eigenvectors were solved. In the process of principal component analysis and number selection in steps 4 and 5 , the characteristics values were ranked as $\left\{\lambda_{1}, \lambda_{1}, \lambda_{1}, \ldots\right\}$ 
from small to large, and several larger characteristics values were selected, and their contribution rate was calculated.

$$
\mu_{(p)}=\frac{\lambda_{1}+\lambda_{2}+\ldots+\lambda_{p}}{m}
$$

where $m$ is the number of principal components.

\subsection{Test Materials for Aize Seeds Characteristics}

We focused on the measurement and analysis of the characteristic physical parameters of typical maize seeds in a cold area of North China and selected 15 kinds of maize varieties as the test materials. We focused on the investigation of different maize varieties in different temperature zones in Heilongjiang Province, China. The accumulated temperature zone is calculated as the sum of the daily average temperature during periods with a daily average temperature $\geq 10^{\circ} \mathrm{C}$ in a year, that is, the sum of active temperature, is referred to as accumulated temperature. It is an index used to study the relationship between temperature and the growth and development speed of biological organisms from two aspects: intensity and action time [31]. The first accumulated temperature zone $\left(\geq 2700^{\circ} \mathrm{C}\right)$ included Xianyu335, Zhongdan909 and Xiangyu998. The second accumulated temperature zone $\left(2500-2700^{\circ} \mathrm{C}\right)$ included Zhengxianda408, Jingnongke728, and Xianyu696. The third accumulated temperature zone $\left(2300-2500{ }^{\circ} \mathrm{C}\right)$ included Suiyu23, Fuer116, and Dongnong259. The forth accumulated temperature zone $\left(2100-2300{ }^{\circ} \mathrm{C}\right)$ included Dongnong254, Demeiya3, and Longfuyu9; and the fifth and sixth accumulated temperature zones $\left(\leq 2100^{\circ} \mathrm{C}\right)$ included Demeiya1, Xinkeyu1, and Keyu16. The above varieties were provided by the Northeast Agricultural University, Heilongjiang Academy of Agricultural Sciences and Beidahuang Seed Industry Group Co., Ltd. Through manual grading and cleaning treatment, the shape of the tested maize seeds was uniform, full, and free of damage. The distribution of each temperate zone and variety number are shown in Table 1.

Table 1. Selection and number of maize varieties in a cold area of China.

\begin{tabular}{|c|c|c|}
\hline No. & Accumulated Temperature Zone in Cold Area & Variety Name \\
\hline $\begin{array}{l}1 \\
2 \\
3\end{array}$ & $\begin{array}{l}\text { First accumulated temperature zone } \\
\qquad\left(\geq 2700^{\circ} \mathrm{C}\right)\end{array}$ & $\begin{array}{c}\text { Xianyu335 } \\
\text { Zhongdan909 } \\
\text { Xiangyu998 }\end{array}$ \\
\hline $\begin{array}{l}4 \\
5 \\
6\end{array}$ & $\begin{array}{l}\text { Second accumulated temperature zone } \\
\qquad\left(2500-2700^{\circ} \mathrm{C}\right)\end{array}$ & $\begin{array}{c}\text { Xianzhengda408 } \\
\text { Jingnongke728 } \\
\text { Xianyu696 }\end{array}$ \\
\hline $\begin{array}{l}7 \\
8 \\
9\end{array}$ & $\begin{array}{l}\text { Third accumulated temperature zone } \\
\qquad\left(2300-2500{ }^{\circ} \mathrm{C}\right)\end{array}$ & $\begin{array}{c}\text { Suiyu23 } \\
\text { Fuer116 } \\
\text { Dongnong259 }\end{array}$ \\
\hline $\begin{array}{l}10 \\
11 \\
12\end{array}$ & $\begin{array}{l}\text { Forth accumulated temperature zone } \\
\qquad\left(2100-2300{ }^{\circ} \mathrm{C}\right)\end{array}$ & $\begin{array}{c}\text { Dongnong254 } \\
\text { Demeiya3 } \\
\text { Longfuyu9 }\end{array}$ \\
\hline $\begin{array}{l}13 \\
14 \\
15\end{array}$ & $\begin{array}{l}\text { Fifth and sixth accumulated temperature zones } \\
\qquad\left(\leq 2100^{\circ} \mathrm{C}\right)\end{array}$ & $\begin{array}{c}\text { Demeiya1 } \\
\text { Xinkeyu1 } \\
\text { Keyu16 }\end{array}$ \\
\hline
\end{tabular}

\subsection{Selection of Physical Characteristics of Maize Seeds and Test Instrument}

The basic parameters of physical maize seeds characteristics mainly include thousand grain weight, moisture content, density, and geometry size. The tribological parameters include the coefficient of static friction, coefficient of rolling friction, angle of natural repose, etc. The mechanical parameters include the coefficient of restitution, stiffness coefficient, and the modulus of elasticity. The physical properties of maize seeds also include their rheological, thermal, optical, electrical, and comminution properties [32]. Based on the 
comprehensive analysis of the correlation between the characteristics and the design of mechanical components, eight physical characteristics indexes, i.e., the thousand-grain weight, moisture content, triaxial arithmetic mean particle size, coefficient of static friction, coefficient of rolling friction, angle of natural repose, coefficient of restitution, and stiffness coefficient, were selected as indexes in this study.

1. Thousand-grain weight (g) is an important index used to measure the weight and plumpness of 1000 maize seeds [33]. It is also an important factor that affects the mechanical characteristics of materials, mainly related to variety, shape, size, plumpness, bulk density, and moisture content.

2. Moisture content (\%) is used to assess the quantity of water in maize seeds. Wet basis representation was applied in this study.

3. Triaxial arithmetic mean particle size $(\mathrm{mm})$ : Large differences exist in the geometrical dimensions along the three axes of a seed. The axial dimension method was mainly used to determine the shape characteristics seeds; establish the three-dimensional coordinate system; define the length, width, and thickness; and measurement of the maize seeds. The calculation of the triaxial arithmetic mean particle size comprehensively reflects the length, width, and thickness of maize seed.

4. The coefficient of static friction reflects the friction characteristics between a maize seed and the contact surface, and is the main parameter used to characterize the friction and scattering characteristics. It is mainly related to the surface roughness of the contact body and directly affects the movement trend of maize seeds [34]. A test bench for measuring the coefficient of static friction was set up using the inclined plane method.

5. The coefficient of rolling friction shows that, when maize seeds roll or have the tendency to roll relative to the surface of the contact body, the rolling is hindered by the deformation of the contact part under pressure [35]. Based on the law of energy conservation, high-speed camera technology was used to build a test bench for measuring the coefficient of rolling friction between the maize seeds.

6. The angle of natural repose $\left({ }^{\circ}\right)$ is also an important parameter reflecting the friction between maize seeds and the flow characteristics of maize seeds. The larger the value, the greater the friction resistance between seeds, and the smaller the tendency toward free dispersion [36]. Injection method was used to determine the angle of natural repose of maize seeds.

7. The coefficient of restitution reflects the ability of maize seeds to return to their original shape after collision and deformation. The larger the value, the stronger the ability to restore shape after deformation and the higher the elasticity of maize seeds after collision [37]. A test bench was built to measure the coefficient of restitution.

8. Stiffness coefficient $(\mathrm{N} / \mathrm{mm})$ : Under the action of external force, the basic parameters of elastic deformation behavior of maize seeds reflect their resistance to elastic deformation, which also characterizes the mechanical damage limit of maize seeds [38]. The stiffness coefficients of maize seeds in horizontal, lateral, and vertical laying were measured by an electronic texture analyzer.

The experiment instruments in this study mainly included an electronic analytical balance (FC204, Shanghai Precision Scientific Instrument Co., Ltd., Shanghai, China. accuracy of $0.001 \mathrm{~g}$ ), a halogen moisture tester automatic (DHS-16, Shanghai JINGHAI Instrument Co., Ltd., Shanghai, China. accuracy of $0.02 \%$ ), an automatic microcomputer seed counter (SLY-C, Zhejiang TOP Instrument Co., Ltd., Zhejiang, China. count speed $\geq 1000 / \mathrm{min}$ ), a Vernier caliper (Shanghai SHOUFENG Precision Instrument Co., Ltd., Shanghai, China. accuracy of $0.01 \mathrm{~mm}$ ), a digital inclinometer (SANHE, Resolution of $0.05^{\circ}$, accuracy of $\pm 0.2^{\circ}$ ), a high-speed camera (Vision research Co., Ltd., Wayne, New Jersey, USA), a computer (Hewlett-Packard), an electric blast drying oven (DHG-9053A, Shanghai YIHENG Scientific Instrument Co., Ltd. Palo Alto, CA, USA), a micromaterial crusher (FZ102, Tianjin TAISITE Instrument Co., Ltd., Tianjin, China), a microcomputer-controlled electronic texture analyzer (TA.XT.plus, Stable Micro systems Co., Ltd., London, UK), a static-friction test bench, 
a rolling-friction test bench, a collision-recovery test bench, and a free-injection test bench. The principles, methods, and instruments used for measuring the physical characteristics of maize seeds are shown in Table 2.

Table 2. Principles, methods, and instruments used for measuring the physical characteristics of maize seeds.

\begin{tabular}{|c|c|c|c|}
\hline No. & Project & Test Principles and Methods & Instrument and Test Bench \\
\hline 1 & $\begin{array}{c}\text { Thousand-grain } \\
\text { weight }\end{array}$ & $\begin{array}{l}\text { The maize seeds were scattered on an imaging disk and } \\
\text { placed on an electronic balance with an RS232 } \\
\text { communication line. When it was stable, the weight data } \\
\text { were sent to the computer, and the number of seeds in the } \\
\text { viewing area was analyzed synchronously. Then, the } \\
\text { thousand-grain weight of maize seeds was obtained (GB/T } \\
5519-2008 \text { Cereals and pulses-Determination of the mass } \\
\text { of } 1000 \text { grains). }\end{array}$ & \\
\hline 2 & Moisture content & $\begin{array}{l}\text { High temperature drying method: We selected maize seeds } \\
\text { to measure the total mass before drying, and used the } \\
\text { micromaterial grinder to crush and grind the maize seeds, } \\
\text { we placed the crushed maize seeds into the electric blast } \\
\text { drying oven, and adjusted it to } 103^{\circ} \mathrm{C} \text { for drying for } 3-4 \mathrm{~h} \text {, } \\
\text { and then weighed it again to determine the total mass after } \\
\text { drying (GB/T } 10362-2008 \text { Inspection of grain and } \\
\text { oils-Determination of moisture content of maize). }\end{array}$ & $\begin{array}{r}-0 \\
\vdots \\
0 \\
0\end{array}$ \\
\hline
\end{tabular}

3 Triaxial arithmetic mean particle size
We selected more than 500 maize seeds at random, and used a Vernier caliper to measure the geometric dimensions (length, width, and thickness) of the maize seeds, with an accuracy of $0.01 \mathrm{~mm}$.

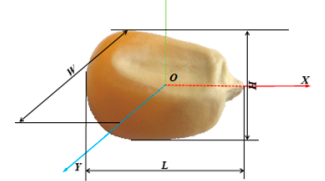

We constructed the maize seeds material platform, adjusted the platform surface to the horizontal position, placed one maize seed on the surface, ensured the same direction, lifted the platform slowly until the maize seed had a sliding trend, and recorded the inclination of the platform surface [39].

We constructed the maize seeds material roller and platform, reduced the energy loss caused by relative sliding and friction, approximately adjusted the platform to $45^{\circ}$ by rolling, and collected the coordinate value and instantaneous speed of the maize roller center point in the process of movement with a high-speed camera test [40].
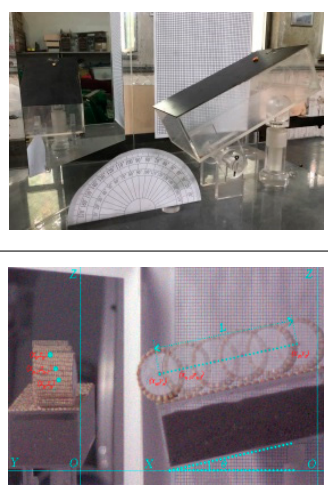

Discharge method: We placed the cylinder on the flat plate vertically, placed maize seeds in the cylinder, and the cylinder moved at a slow speed perpendicular to the plate. We captured photos of the maize seeds in three-dimensional space. MATLAB software was used to process image noise, gray scale, and binary, and fit the envelope curve equation (GB/T 11986-1989 Surface active agents-Powders and granules-Measurement of the angle of repose).

Speed definition method: We constructed the maize seeds material platform, adjusted it to $45^{\circ}$ with the horizontal plane; we dropped one maize seed freely to the platform at a certain height, which collided with the platform, forming a parabola movement after rebound, and finally falling to the ground. We measured parameters such as the horizontal and vertical displacements of the maize seed falling to the ground [41]. 
Table 2. Cont.

\begin{tabular}{lll}
\hline No. & Project & \multicolumn{1}{c}{ Test Principles and Methods } \\
\hline & $\begin{array}{l}\text { The maize seeds were placed on the platform in all } \\
\text { directions to ensure that the center of the maize seed was } \\
\text { aligned with the center of the plate indenter of the analyzer. } \\
\text { The pressure head was set to decrease steadily and } \\
\text { compress the maize seeds. The load and displacement } \\
\text { parameters at all times were automatically collected and } \\
\text { recorded, and the curve of the compression load } \\
\text { displacement relationship of maize seeds was drawn in real } \\
\text { time [42]. }\end{array}$ \\
&
\end{tabular}

During the test, the methods and instruments in Table 2 were used to determine and analyze the physical characteristics of 15 maize varieties. Excel 2013 and SPSS 22.0 software were used to analyze the data, and principal component analysis and cluster analysis were conducted. Through the analysis and simplification of the physical characteristics index, an effective and scientific evaluation system was constructed, and the comprehensive scores of each variety were obtained. The maize varieties with excellent comprehensive physical characteristics and suitable for mechanized planting were selected.

\section{Results}

\subsection{Results of Physical Maize Seeds Characteristics}

Eight physical characteristic parameters, such as thousand-grain weight, moisture content, triaxial arithmetic mean particle size, and coefficient of static friction, of the 15 kinds of selected maize seeds from a cold region are shown in Table 3.

According to the analysis of the test results in Table 3, the average thousand-grain weight of each maize variety was $353.19 \mathrm{~g}$, ranging from 295.92-418.9 g, with larger variation. The average value of moisture content was $12.30 \%$, with a range of $11.20-13.05 \%$, with small variation. The average triaxial arithmetic mean particle size was $8.62 \mathrm{~mm}$ $(7.84-9.80 \mathrm{~mm})$, with large variation. The average coefficient of static friction was 0.29 , stable at $0.24-0.34$, with large variation. The average coefficient of rolling friction was 0.07 , stable at $0.053-0.083$, with large variation. The average natural repose angle was $23.11^{\circ}$, stable at $20.37-24.59^{\circ}$, with large variation. The average coefficient of restitution was 0.40 , stable at $0.332-0.471$, with large variation. The average value of stiffness coefficient was $89.85 \mathrm{~N} / \mathrm{mm}$, stable at $78.5-102.23 \mathrm{~N} / \mathrm{mm}$, with large variation. 
Table 3. Parameters of physical characteristics of typical maize seeds in cold area.

\begin{tabular}{|c|c|c|c|c|c|c|c|c|c|c|c|c|c|c|c|c|}
\hline \multirow{2}{*}{ Index } & \multirow{2}{*}{$\begin{array}{l}\text { Statistical } \\
\text { Analysis }\end{array}$} & \multicolumn{15}{|c|}{ Typical Maize Seeds in Cold Region } \\
\hline & & 1 & 2 & 3 & 4 & 5 & 6 & 7 & 8 & 9 & 10 & 11 & 12 & 13 & 14 & 15 \\
\hline \multirow{3}{*}{$\begin{array}{c}\text { Thousand grain } \\
\text { weight, } \\
\text { g }\end{array}$} & Mean & 342.80 & 339.21 & 402.68 & 357.13 & 313.83 & 370.49 & 348.69 & 418.90 & 360.80 & 366.46 & 370.43 & 340.63 & 331.08 & 295.92 & 338.75 \\
\hline & $\mathrm{SD}$ & 1.32 & 1.04 & 1.42 & 0.69 & 0.56 & 1.52 & 0.34 & 0.81 & 1.55 & 2.43 & 0.15 & 1.23 & 1.89 & 0.55 & 1.59 \\
\hline & $\mathrm{CV}, \%$ & 0.39 & 0.31 & 0.35 & 0.19 & 0.18 & 0.41 & 0.98 & 0.19 & 0.43 & 0.67 & 0.40 & 0.36 & 0.57 & 0.19 & 0.47 \\
\hline \multirow{3}{*}{$\begin{array}{l}\text { Moisture } \\
\text { content, } \%\end{array}$} & Mean & 12.13 & 11.94 & 13.02 & 12.47 & 12.42 & 12.88 & 11.74 & 13.05 & 12.61 & 11.42 & 12.90 & 12.37 & 11.60 & 11.20 & 12.74 \\
\hline & SD & 0.66 & 0.58 & 0.64 & 0.52 & 0.60 & 0.99 & 0.47 & 1.29 & 0.34 & 0.48 & 0.35 & 1.44 & 0.83 & 0.27 & 0.12 \\
\hline & $C V, \%$ & 5.44 & 4.86 & 4.92 & 4.17 & 4.83 & 7.69 & 4.00 & 9.89 & 0.03 & 4.20 & 2.71 & 11.64 & 7.16 & 2.41 & 0.94 \\
\hline \multirow{4}{*}{$\begin{array}{c}\text { Triaxial } \\
\text { arithmetic } \\
\text { mean particle } \\
\text { size, } \mathrm{mm}\end{array}$} & Mean & 8.33 & 8.35 & 9.16 & 8.45 & 8.45 & 9.46 & 8.20 & 9.80 & 8.37 & 8.63 & 9.10 & 8.56 & 8.32 & 7.84 & 8.34 \\
\hline & SD & 0.31 & 0.52 & 0.32 & 0.21 & 0.23 & 0.51 & 0.09 & 0.34 & 0.42 & 0.23 & 0.32 & 0.06 & 0.47 & 0.20 & 0.23 \\
\hline & $\mathrm{CV} / \%$ & 3.72 & 6.22 & 3.49 & 2.49 & 2.72 & 5.39 & 1.10 & 3.47 & 5.02 & 2.67 & 3.52 & 0.70 & 5.65 & 2.55 & 2.76 \\
\hline & Mean & 0.27 & 0.30 & 0.29 & 0.34 & 0.24 & 0.25 & 0.32 & 0.29 & 0.30 & 0.28 & 0.29 & 0.26 & 0.28 & 0.25 & 0.33 \\
\hline \multirow{2}{*}{$\begin{array}{l}\text { Coefficient of } \\
\text { static friction }\end{array}$} & SD & 0.05 & 0.03 & 0.07 & 0.03 & 0.01 & 0.06 & 0.03 & 0.03 & 0.05 & 0.02 & 0.03 & 0.05 & 0.05 & 0.09 & 0.08 \\
\hline & $\mathrm{CV}, \%$ & 18.52 & 10.00 & 24.14 & 8.82 & 4.17 & 24.00 & 9.38 & 10.34 & 16.67 & 7.14 & 10.34 & 19.23 & 25.00 & 36.00 & 24.24 \\
\hline \multirow{3}{*}{$\begin{array}{l}\text { Coefficient of } \\
\text { rolling friction }\end{array}$} & Mean & 0.069 & 0.071 & 0.083 & 0.075 & 0.067 & 0.078 & 0.075 & 0.072 & 0.080 & 0.080 & 0.081 & 0.067 & 0.062 & 0.053 & 0.078 \\
\hline & SD & 0.02 & 0.02 & 0.03 & 0.02 & 0.01 & 0.03 & 0.02 & 0.01 & 0.01 & 0.01 & 0.02 & 0.01 & 0.01 & 0.02 & 0.03 \\
\hline & $C V, \%$ & 28.98 & 28.17 & 36.14 & 26.67 & 14.93 & 38.46 & 26.67 & 13.89 & 12.50 & 12.50 & 24.69 & 14.93 & 16.13 & 37.74 & 38.46 \\
\hline \multirow{2}{*}{$\begin{array}{c}\text { Angle of } \\
\text { natural repose, } \\
\circ\end{array}$} & SD & 0.43 & 1.62 & 1.59 & 2.31 & 1.96 & 2.90 & 1.48 & 1.94 & 2.04 & 0.59 & 1.00 & 0.94 & 1.54 & 1.56 & 1.88 \\
\hline & $C V, \%$ & 1.78 & 7.03 & 6.47 & 9.97 & 8.79 & 12.22 & 6.42 & 8.14 & 8.43 & 2.47 & 4.13 & 4.15 & 6.94 & 7.32 & 9.23 \\
\hline \multirow{3}{*}{$\begin{array}{l}\text { Coefficient of } \\
\text { restitution }\end{array}$} & Mean & 0.471 & 0.406 & 0.428 & 0.390 & 0.332 & 0.403 & 0.415 & 0.425 & 0.372 & 0.385 & 0.455 & 0.374 & 0.382 & 0.398 & 0.390 \\
\hline & SD & 0.03 & 0.01 & 0.01 & 0.03 & 0.01 & 0.02 & 0.01 & 0.02 & 0.01 & 0.01 & 0.02 & 0.04 & 0.03 & 0.02 & 0.01 \\
\hline & $C V, \%$ & 6.37 & 2.46 & 2.34 & 7.69 & 3.01 & 4.96 & 2.41 & 4.71 & 2.69 & 2.60 & 4.40 & 10.70 & 7.85 & 5.03 & 2.56 \\
\hline \multirow{3}{*}{$\begin{array}{l}\text { Stiffness } \\
\text { coefficient, } \\
\mathrm{N} / \mathrm{mm}\end{array}$} & Mean & 79.83 & 98.26 & 100.11 & 89.25 & 94.36 & 102.23 & 84.35 & 97.26 & 80.05 & 81.06 & 98.41 & 83.74 & 98.37 & 78.50 & 81.92 \\
\hline & SD & 0.22 & 0.21 & 0.33 & 0.10 & 0.08 & 0.21 & 0.41 & 0.06 & 0.20 & 0.42 & 0.09 & 0.22 & 0.31 & 0.29 & 0.12 \\
\hline & $C V, \%$ & 0.28 & 0.21 & 0.33 & 0.11 & 0.08 & 0.21 & 0.49 & 0.06 & 0.25 & 0.52 & 0.09 & 0.26 & 0.36 & 0.37 & 0.15 \\
\hline
\end{tabular}

"Mean" is the mean value of each parameter; "SD" is the standard deviation; "CV" is the coefficient of variation. 


\subsection{Principal Component Analysis of Physical Maize Seeds Characteristics}

The SPSS 22.0 software was used to perform the principal component analysis of the physical characteristics of maize seeds [43]. The process was as follows: 1 . index data normalization and standardization, 2. using SPSS software, the Correlation Matrix module, to judge the correlation; 3 . determining the number of principal components, using the Total Variance Explained module in the SPSS to calculate the cumulative contribution rate of the principal component variance $\geq 80 \%$, and combining the Component Matrix module with no loss of variables to determine the number of principal components $m ; 4$. determining principal component $Z_{i}$ expression, dividing the $i$ th column vector in the Component Matrix module of SPSS by the open root of the $i$ th characteristic root to obtain the variable coefficient vector of the $i$ th principal component $Z_{i}$ (in the Transform-compute module), obtaining the principal component $Z_{i}$ expression; 5 . naming principal component $Z_{i}$ and naming the corresponding variable with a large absolute value of the coefficient in the $i$ th column of the Component Matrix in SPSS; 6 . The principal component and integrated principal $Z_{t}=\sum_{i=1}^{m}\left(\lambda_{i} / p\right) Z_{i}, \lambda_{i} / p$ is in the $\%$ of variance of the Initial Eigenvalues in the Total Variance Explained modules of SPSS software, $\operatorname{Var}_{t}=\left(\sum_{i=1}^{m} \lambda_{i}^{3}\right) p^{2} ; 7$. examination, combining the actual results and experience of the comprehensive principal component evaluation value to test the original data.

SPSS 22.0 software was used to obtained the correlation coefficient matrix, variance contribution analysis table, principal component load matrix, and eigenvector of each index parameter, as shown in Tables 4-6.

Table 4. Correlation coefficient matrix between the main physical characteristic parameters of maize seeds.

\begin{tabular}{|c|c|c|c|c|c|c|c|c|}
\hline Index & $\begin{array}{c}\text { Thousand- } \\
\text { Grain } \\
\text { Weight }\end{array}$ & $\begin{array}{c}\text { Moisture } \\
\text { Content }\end{array}$ & $\begin{array}{c}\text { Triaxial } \\
\text { Arithmetic } \\
\text { Mean } \\
\text { Particle Size }\end{array}$ & $\begin{array}{l}\text { Coefficient } \\
\text { of Static } \\
\text { Friction }\end{array}$ & $\begin{array}{l}\text { Coefficient } \\
\text { of Rolling } \\
\text { Friction }\end{array}$ & $\begin{array}{c}\text { Angle of } \\
\text { Natural } \\
\text { Repose }\end{array}$ & $\begin{array}{l}\text { Coefficient } \\
\text { of } \\
\text { Restitution }\end{array}$ & $\begin{array}{l}\text { Stiffness } \\
\text { Coefficient }\end{array}$ \\
\hline $\begin{array}{l}\text { Thousand } \\
\text { grain } \\
\text { weight }\end{array}$ & 1.000 & & & & & & & \\
\hline $\begin{array}{l}\text { Moisture } \\
\text { content }\end{array}$ & 0.657 * & 1.000 & & & & & & \\
\hline $\begin{array}{c}\text { Triaxial } \\
\text { arithmetic } \\
\text { mean } \\
\text { particle size }\end{array}$ & $0.856^{* *}$ & $0.733^{* *}$ & 1.000 & & & & & \\
\hline $\begin{array}{l}\text { Coefficient } \\
\text { of static } \\
\text { friction }\end{array}$ & 0.284 & 0.164 & -0.095 & 1.000 & & & & \\
\hline $\begin{array}{l}\text { Coefficient } \\
\text { of rolling } \\
\text { friction }\end{array}$ & $0.700^{* *}$ & 0.604 * & 0.500 & 0.473 & 1.000 & & & \\
\hline $\begin{array}{l}\text { Angle of } \\
\text { natural } \\
\text { repose }\end{array}$ & 0.691 * & 0.349 & 0.545 & -0.034 & 0.550 & 1.000 & & \\
\hline $\begin{array}{l}\text { Coefficient } \\
\text { of } \\
\text { restitution }\end{array}$ & 0.423 & 0.188 & 0.302 & 0.175 & 0.225 & 0.476 & 1.000 & \\
\hline $\begin{array}{l}\text { Stiffness } \\
\text { coefficient }\end{array}$ & 0.429 & 0.469 & $0.655^{*}$ & -0.112 & 0.209 & 0.293 & 0.106 & 1.000 \\
\hline
\end{tabular}


Table 5. Variance contribution analysis table.

\begin{tabular}{ccccccc}
\hline \multirow{2}{*}{ Component } & \multicolumn{3}{c}{ Initial Characteristics Value } & \multicolumn{3}{c}{ Extract Square Sum Loading } \\
\cline { 2 - 6 } & Total & Variance, $\%$ & Cumulative, $\%$ & Total & Variance, \% & Cumulative, \% \\
\hline 1 & 4.018 & 50.222 & 50.222 & 4.018 & 50.222 & 50.222 \\
2 & 1.406 & 17.579 & 67.801 & 1.406 & 17.579 & \\
3 & 1.035 & 12.935 & 80.736 & 1.035 & & \\
4 & 0.631 & 7.881 & 88.617 & & & \\
5 & 0.443 & 5.543 & 94.160 & & & \\
6 & 0.283 & 3.531 & 97.692 & & & \\
7 & 0.165 & 2.065 & 99.757 & & & \\
8 & 0.019 & 0.243 & 100.000 & & & \\
\hline
\end{tabular}

Table 6. Load matrix and eigenvector of each principal component.

\begin{tabular}{ccccccc}
\hline \multirow{2}{*}{ Test Index } & \multicolumn{2}{c}{ Principal Component Load Matrix } & \multicolumn{3}{c}{ Principal Component Eigenvector } \\
\cline { 2 - 6 } & $\mathbf{Z}_{\mathbf{1}}$ & $\mathbf{Z}_{\mathbf{2}}$ & $\mathbf{Z}_{\mathbf{3}}$ & $\mathbf{Z}_{\mathbf{1}}$ & $\mathbf{Z}_{\mathbf{2}}$ & $\mathbf{Z}_{\mathbf{3}}$ \\
\hline Thousand-grain weight & 0.938 & 0.087 & 0.024 & 0.468 & 0.073 & 0.024 \\
Moisture content & 0.798 & -0.071 & -0.372 & 0.398 & -0.060 & -0.366 \\
Triaxial arithmetic mean particle size & 0.883 & -0.359 & -0.071 & 0.441 & -0.303 & -0.070 \\
Coefficient of static friction & 0.221 & 0.859 & -0.283 & 0.110 & 0.724 & -0.278 \\
Coefficient of rolling friction & 0.766 & 0.423 & -0.201 & 0.382 & 0.357 & -0.198 \\
Angle of natural repose & 0.734 & -0.020 & 0.472 & 0.366 & -0.017 & 0.464 \\
Coefficient of restitution & 0.475 & 0.229 & 0.705 & 0.237 & 0.193 & 0.693 \\
Stiffness coefficient & 0.580 & -0.544 & -0.225 & 0.289 & -0.459 & -0.221 \\
\hline
\end{tabular}

We concluded that there were obvious differences in the physical characteristic parameters of the maize varieties, and there were different degrees of correlation. We found a significant difference in the thousand-grain weight among the different varieties of maize. The higher the moisture content, the higher the thousand-grain weight. Triaxial arithmetic mean particle size was positively correlated with thousand-grain weight and moisture content. The coefficient of static friction was positively correlated with the thousand-grain weight and moisture content and was negatively correlated with the triaxial arithmetic mean particle size. The coefficient of rolling friction was positively correlated with the thousand-grain weight, moisture content, triaxial arithmetic mean particle size, and coefficient of static friction. Both the angle of natural repose and the stiffness coefficient were negatively correlated with the coefficient of static friction. We identified different degrees of correlation between maize seeds physical characteristics, which showed that the information reflected overlaps and interweaves, and each single index parameter had a different effect on the physical maize seed characteristics, so we were unable to directly and comprehensively evaluate the maize seeds' physical characteristics using the above indexes.

On this basis, principal component analysis was conducted for the eight physical parameters of the 15 maize varieties. The variance of the principal component was taken as the characteristic's value, indicating how much the corresponding component can describe the original information. The larger the characteristic value of the principal component, the more information contained by the variable [44]. The scree plot of principal component analysis is shown in Figure 1. The characteristic value can reflect the corresponding relationship between the characteristic value of the correlation matrix of the index and the principal component number. Combined with the principal component load matrix and the eigenvector, the first three characteristic values of the principal component were all greater than one, and the cumulative contribution rate was more than $80 \%$, which represented the information from the raw data of the physical characteristics of maize. According to the bottom lithotripsy map, there is an inflection point at the third principal component. After the fourth principal component, the characteristic values are small and close to each other. According to the cumulative contribution rate, the cumulative contribution rate of the first 
three principal components was $80.736 \%$. Therefore, the first three principal components were selected to comprehensively evaluate the physical characteristics of maize seeds.

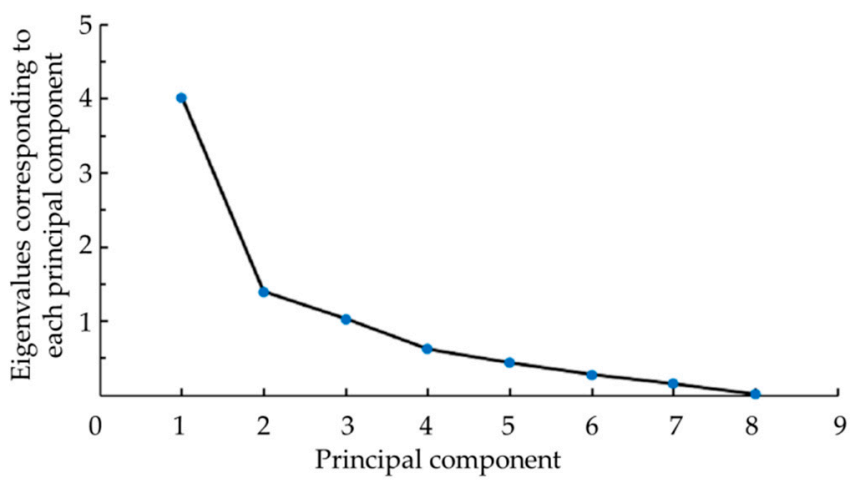

Figure 1. Scree plot of principal component analysis: The $X$ axis is the principal component; The $Y$ axis is the eigenvalues corresponding to each principal component-the amount of each principal component contributed. Generally, the principal component with characteristic value greater than one is selected for evaluation.

Based on a series of processing and analyses, and combined with the load matrix and eigenvector of each principal component in Table 6, the relationships between the principal component and the corresponding variable were obtained, and the linear equations between each principal component and the physical characteristics indexes of maize seeds was constructed.

1. The first principal component was:

$$
\begin{gathered}
Z_{1}=0.468 X_{1}+0.398 X_{2}+0.441 X_{3}+0.110 X_{4}+0.382 X_{5}+0.366 X_{6}+0.237 X_{7}+ \\
0.289 X_{8}
\end{gathered}
$$

2. The second principal component was:

$$
\begin{gathered}
Z_{2}=0.073 X_{1}-0.060 X_{2}-0.303 X_{3}+0.724 X_{4}+0.357 X_{5}-0.017 X_{6}+0.193 X_{7}- \\
0.459 X_{8}
\end{gathered}
$$

3. The third principal component was:

$$
\begin{gathered}
Z_{3}=0.024 X_{1}-0.366 X_{2}-0.070 X_{3}-0.278 X_{4}-0.198 X_{5}+0.464 X_{6}+0.693 X_{7}- \\
0.221 X_{8}
\end{gathered}
$$

According to the analysis of variance contribution, the first principal component accounted for $50.222 \%$, which contained a large amount of information. It mainly included the thousand grain weight, triaxial arithmetic mean particle size, moisture content, coefficient of rolling friction, and the angle of natural repose. The second principal component accounted $17.579 \%$, which mainly included the coefficient of static friction and stiffness coefficient. The third principal component accounted for $12.935 \%$, which mainly included the coefficient of restitution. Combining the principal component coefficient and its corresponding variance contribution rate, the comprehensive evaluation formula was established as $Z=0.502 Z_{1}+$ $0.176 Z_{2}+0.129 Z_{3}$. The comprehensive scores of the physical maize seeds characteristics in this cold region could be obtained through the evaluation formula.

According to the comprehensive scores, the maize varieties in the cold area were sorted, as shown in Table 7. Combining the analysis results with the performance of maize varieties in the mechanized planting process, the evaluation standard of the eight physical characteristics of 15 maize varieties in a cold region were determined. A comprehensive 
score $\geq 110$ was level 1, 105-110 was level 2, 100-105 was level 3, 95-100 was level 4, and a comprehensive score $\leq 95$ was level 5 . So, the order of maize varieties was: Fuer116 > Xiangyu998 $>$ Xianyu696 > Demeiya3 $>$ Dongnong254 $>$ Dongnong259 $>$ Xianzhengda408 $>$ Suiyu23 $>$ Xianyu335 $>$ Zhongdan909 $>$ Longfuyu9 $>$ Keyu16 $>$ Demeiya1 $>$ Jingnongke728 $>$ Xinkeyu1.

Table 7. Principal component scores and composite scores.

\begin{tabular}{cccccc}
\hline \multirow{2}{*}{ Variety } & \multicolumn{3}{c}{ Principal Component } & \multirow{2}{*}{$\begin{array}{c}\text { Composite } \\
\text { Score }\end{array}$} & Rating Level \\
\cline { 2 - 4 } & $\mathbf{Z}_{\mathbf{1}}$ & $\mathbf{Z}_{\mathbf{2}}$ & $\mathbf{Z}_{\mathbf{3}}$ & & \\
\hline Fuer116 & 242.548 & -17.899 & -5.652 & 117.880 & 1 \\
Xiangyu998 & 235.772 & -20.208 & -6.257 & 113.994 & 1 \\
Xianyu696 & 221.070 & -23.636 & -7.871 & 105.802 & 2 \\
Demeiya3 & 219.988 & -21.747 & -6.755 & 105.735 & 2 \\
Dongnong254 & 212.159 & -13.852 & -2.669 & 103.722 & 3 \\
Dongnong259 & 209.708 & -13.790 & -2.846 & 102.479 & 3 \\
Xianzhengda408 & 210.261 & -18.252 & -5.390 & 101.643 & 3 \\
Suiyu23 & 204.450 & -16.504 & -4.264 & 99.179 & 4 \\
Xianyu335 & 201.034 & -14.971 & -2.965 & 97.902 & 4 \\
Zhongdan909 & 204.167 & -23.654 & -7.660 & 97.341 & 4 \\
Longfuyu9 & 200.739 & -17.008 & -4.784 & 97.161 & 4 \\
Keyu16 & 198.572 & -16.168 & -5.606 & 96.115 & 4 \\
Demeiya1 & 199.930 & -24.282 & -8.145 & 95.04 & 4 \\
Jingnongke728 & 191.107 & -23.827 & -7.956 & 90.716 & 5 \\
Xinkeyu1 & 177.037 & -17.563 & -4.806 & 85.162 & 5 \\
\hline
\end{tabular}

\subsection{Cluster Analysis of Typical Maize in Cold Area}

In this context, we conducted a cluster analysis of the 15 maize varieties. According to the comprehensive physical characteristics parameters, the cluster results can be used to judge the intimate relationship according to the comprehensive physical characteristic parameters to better understand the nature of the data [45]. First, the physical characteristics of maize seeds were analyzed by principal component analysis, and the highdimensional data were transformed into low-dimensional data. The Euclidean distance showed a good effect on the status data, so we used the Euclidean distance [46]. Using the discrete sum of squares method, all varieties of maize were divided into four categories at the Euclidean distance of 5.0, as shown in Figure 2. Xianyu696 and Demeiya3 were classified into one group; Dongnong259, Dongnong254, Xianzhengda408, Zhongdan909, Demeiya1, Longfuyu9, Keyu16, Xianyu335, and Suiyu23 were classified into another group; Jingnongke728 and Xinkeyu1 were classified into a third group; and Xiangyu998 and Fuer116 were classified into a fourth group. Through principal component and cluster analyses, the eight physical characteristics parameters of typical cold-area maize were analyzed. The results showed that the eight physical parameters belong to three principal components, representing $80.736 \%$ of the total variance in the information. The 15 maize varieties were categorized into four groups. Due to the wide differences in the physical characteristics and the Euclidean distance between groups, the principal component complementation and selection of Euclidean distance should be considered in the evaluation of physical characteristics. 


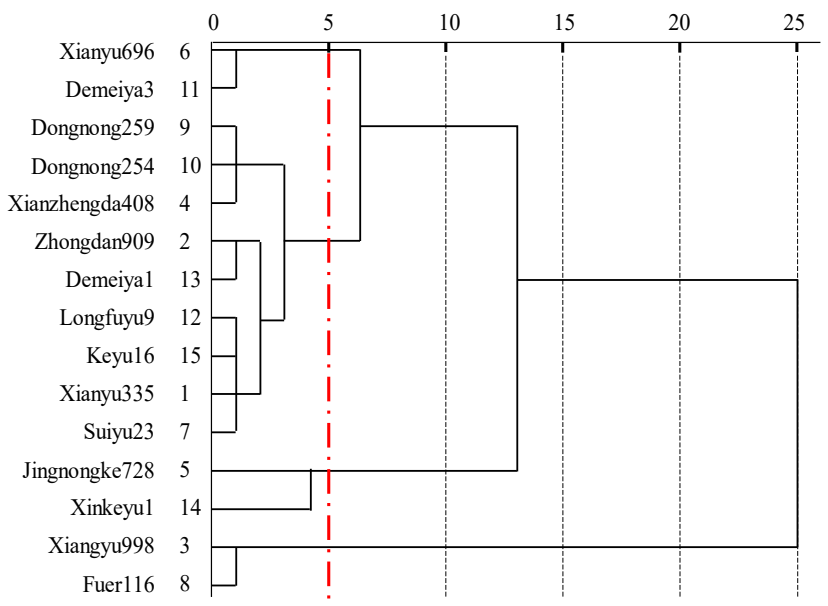

Figure 2. Dendrogram of cluster analysis of the maize seeds of 15 different varieties: 0-25 indicates the range of Euclidean distance, and different Euclidean distances lead to different categories. The red line in the figure indicates that Euclidean distance 5.0 is selected, and the number of branches passed by the red line represents the clustering results of maize seed varieties.

\subsection{Discussion}

In this study, we measured the thousand-grain weight, moisture content, triaxial arithmetic mean particle size, coefficient of static friction, coefficient of rolling friction, angle of natural repose, coefficient of restitution, and stiffness coefficient of 15 varieties of maize seeds. Principal component evaluation and cluster comprehensive analysis were used to simplify the characteristic parameter index, which was then used to judge the comprehensive score of maize seeds. The 15 varieties of maize seeds were clustered into four groups by cluster analysis. The physical characteristics of the different groups were different, and the physical characteristics of the same group showed strong similarity and correlation. Therefore, during food processing, maize seeds of the same group can be processed with the same equipment or control parameters, whereas maize seeds of different groups showed considerable differences, so it would be necessary to adjust the control parameters of the equipment to process maize and produce the same quality product. In addition, if the seeds of the same group are mixed to produce the same taste and quality, it is necessary to analyze the chemical components of different varieties of maize seeds, such as starch, sugar, crude fat, protein, and ash contents. The thermal characteristics of different varieties of maize seeds should also be analyzed to explore the specific heat value changes in different varieties of maize at different temperatures to provide a theoretical basis for the processing and production of maize baking food. Then, it will also be necessary to explore the differences in the gelatinization characteristics of different varieties of maize seeds to control the degree of gelatinization of maize seeds in the process of preparation and improve the forming characteristics of maize-based food. In the future, we will conduct determination research combining physical analysis and chemical analysis to comprehensively, objectively, and systematically evaluate the characteristics of maize seeds, and provide reliable data support for the screening and classification of maize seeds in food processing and production.

With the development of China's modern maize industry, adjusting and optimizing the structure of maize varieties directly affect the application of maize germplasm resources, cultivation technology, protection technology, and post-production processing and utilization of system links, which is crucial for promoting sustainable agricultural development and the moderate-scale management of grain [47]. In this study, the principal component analysis method was used to combine multiple indicators into a few comprehensive indicators. The principal components reflect most of the original variable information, and the information contained is complementary and repeated. In future research, the selection capacity of typical maize seed samples should be continuously increased, and the 
evaluation basis of the physical characteristics of maize seed samples suitable for planting in northern cold areas and the scientific quality of the evaluation should be improved.

\section{Conclusions}

In this study, we focused on the determination of physical characteristics parameters, principal component evaluation, and cluster analysis of typical cold-region maize varieties; judged the comprehensive scores of maize varieties; constructed a scientific and reasonable evaluation system; and obtained the following conclusions:

1. The main physical characteristics parameters of typical cold-region maize varieties differ significantly, and the physical characteristics indicators show different degrees of correlation.

2. Principal component analysis was used to select the first three principal component factors, with a cumulative contribution rate to the total variance of $80.736 \%$, which represented most of the information of the original eight physical characteristics indicators, with good representativeness and objectivity. The comprehensive evaluation formula is $Z=0.502 Z_{1}+0.176 Z_{2}+0.129 Z_{3}$, and the comprehensive score and grade classification of the 15 maize varieties in a cold region were determined.

3. The maize species in a cold region were clustered into four groups by cluster analysis, and the physical characteristics of each group were different. Our findings provide a new idea for the evaluation and analysis of the physical properties of agricultural materials, and provide a new method for the screening and classification of food processing raw materials.

Author Contributions: Conceptualization, J.W., H.T., and C.X.; methodology, H.T. and C.X.; software, Y.J. and Z.W.; validation, L.T.; investigation, C.X. and Z.W.; resources, H.T.; data curation, H.T. and L.T.; writing-original draft preparation, J.W., H.T., and C.X.; writing-review and editing, J.W. and H.T.; visualization, H.T. and C.X.; supervision, J.W. and Z.W.; funding acquisition, H.T. All authors have read and agreed to the published version of the manuscript.

Funding: This work was funded by the National Natural Science Foundation of China (NSFC), grant number: 31901414; the Postdoctoral Science Foundation of Heilongjiang Province, grant number: LBH-Z19007; and the Young Talents Project of Northeast Agricultural University, grant number: 19 QC41.

Institutional Review Board Statement: Not applicable.

Informed Consent Statement: Not applicable.

Data Availability Statement: All data are presented in this article in the form of figures and tables.

Acknowledgments: The authors would like to acknowledge the College of Engineering, Northeast Agricultural University; the College of Agriculture, Northeast Agricultural University; and the Key Laboratory of Crop Harvesting Equipment Technology of Zhejiang Province.

Conflicts of Interest: The authors declare no conflict of interest.

\section{References}

1. Li, Y.; Bingxin, Y.; Yiming, Y.; Xiantao, H.; Quanwei, L.; Zhijie, L.; Xiaowei, Y.; Tao, C.; Dongxing, Z. Global overview of research progress and development of precision maize planters. Int. J. Agric. Biol. Eng. 2016, 9, 9-26. [CrossRef]

2. Wang, J.; Tang, H.; Wang, J. Comprehensive Utilization Status and Development Analysis of Crop Straw Resource in Northeast China. Nongye Jixie Xuebao/Trans. Chin. Soc. Agric. Mach. 2017, 48, 1-21. [CrossRef]

3. Gao, Y.; Zhai, C.; Yang, S.; Zhao, X.; Wang, X.; Zhao, C. Development of CAN-based Downforce and Sowing Depth Monitoring and Evaluation System for Precision Planter. Nongye Jixie Xuebao/Trans. Chin. Soc. Agric. Mach. 2020, 51, 15-28. [CrossRef]

4. Wang, J.; Tang, H.; Zhou, W.; Yang, W.; Wang, Q. Improved design and experiment on pickup finger precision seed metering device. Nongye Jixie Xuebao/Trans. Chin. Soc. Agric. Mach. 2015, 46, 68-76. [CrossRef]

5. Tang, H.; Xu, C.; Wang, J.; Wang, Z.; Han, H.; Li, J. Design and experiment of finger-clip maize no-tillage precision planter. Int. Agric. Eng. J. 2020, 29, 86-97.

6. Yatskul, A.; Lemiere, J.P.; Cointault, F. Influence of the divider head functioning conditions and geometry on the seed's distribution accuracy of the air-seeder. Biosyst. Eng. 2017, 161, 120-134. [CrossRef] 
7. Brown, W.E.; Bradford, B.J. Effects of a high-protein corn product compared with soy and canola protein sources on nutrient digestibility and production responses in mid-lactation dairy cows. J. Dairy Sci. 2020, 103, 6233-6243. [CrossRef]

8. Aboagye, G.; Gbolonyo-Cass, S.; Kortei, N.K.; Annan, T. Microbial evaluation and some proposed good manufacturing practices of locally prepared malted corn drink ("asaana") and Hibiscus sabdarifa calyxes extract ("sobolo") beverages sold at a university cafeteria in Ghana. Sci. Afr. 2020, 8, 1-16. [CrossRef]

9. Kyttä, K.M.; Lakio, S.; Wikström, H.; Sulemanji, A.; Fransson, M.; Ketolainen, J.; Tajarobi, P. Comparison between twin-screw and high-shear granulation-The effect of filler and active pharmaceutical ingredient on the granule and tablet properties. Powder Technol. 2020, 376, 187-198. [CrossRef]

10. Córdova-Noboa, H.A.; Oviedo-Rondón, E.O.; Ortiz, A.; Matta, Y.; Hoyos, J.S.; Buitrago, G.D.; Martinez, J.D.; Yanquen, J.J.; Chico, M.; Martin, V.E.S.; et al. Effects of corn kernel hardness and grain drying temperature on particle size and pellet durability when grinding using a roller mill or hammermill. Anim. Feed Sci. Technol. 2021, 271, 114715. [CrossRef]

11. Han, Y.; Jia, F.; Li, G.; Liu, H.; Li, J.; Chen, P. Numerical analysis of flow pattern transition in a conical silo with ellipsoid particles. Adv. Powder Technol. 2019, 30, 1870-1881. [CrossRef]

12. Gürsoy, S.; Güzel, E. Determination of physical properties of some agricultural grains. Res. J. Appl. Sci. Eng. Technol. 2010, 2, 492-498.

13. Kelley, D.S.; Adkins, Y.; Reddy, A.; Woodhouse, L.R.; Mackey, B.E.; Erickson, K.L. Sweet bing cherries lower circulating concentrations of markers for chronic inflammatory diseases in healthy humans1-4. J. Nutr. 2013, 143, 340-344. [CrossRef]

14. Liu, C.; Wang, Y.; Song, J.; Li, Y.; Ma, T. Experiment and discrete element model of rice seed based on 3D laser scanning. Nongye Gongcheng Xuebao/Trans. Chin. Soc. Agric. Eng. 2016, 32, 294-300. [CrossRef]

15. Abdolahzare, Z.; Abdanan Mehdizadeh, S. Real time laboratory and field monitoring of the effect of the operational parameters on seed falling speed and trajectory of pneumatic planter. Comput. Electron. Agric. 2018, 145, 187-198. [CrossRef]

16. Wang, Y.; Liang, Z.; Zhang, D.; Cui, T.; Shi, S.; Li, K.; Yang, L. Calibration method of contact characteristic parameters for corn seeds based on EDEM. Nongye Gongcheng Xuebao/Trans. Chin. Soc. Agric. Eng. 2016, 32, 36-42. [CrossRef]

17. Wang, J.W.; Han, T.; Wang, J.F.; Jiang, D.X.; Li, X. Measurement and analysis of restitution coefficient between maize seed and soil based on high-speed photography. Int. J. Agric. Biol. Eng. 2017, 10, 102-114. [CrossRef]

18. Ozturk, I.; Kara, M.; Uygan, F.; Kalkan, F. Restitution coefficient of chick pea and lentil seeds. Int. Agrophysics 2010, $24,209-211$.

19. Chen, L.; Ma, X.; Cao, X.; Wen, Z.; Ji, C.; Li, H. Evaluation research of physical characteristics of hybrid rice buds based on principal component analysis. Nongye Gongcheng Xuebao/Trans. Chin. Soc. Agric. Eng. 2019, 35, 334-342. [CrossRef]

20. Ganiyu, S.A.; Badmus, B.S.; Olurin, O.T.; Ojekunle, Z.O. Evaluation of seasonal variation of water quality using multivariate statistical analysis and irrigation parameter indices in Ajakanga area, Ibadan, Nigeria. Appl. Water Sci. 2018, 8, 1-15. [CrossRef]

21. Mounjouenpou, P.; Ngono Eyenga, S.N.N.; Kamsu, E.J.; Bongseh Kari, P.; Ehabe, E.E.; Ndjouenkeu, R. Effect of fortification with baobab (Adansonia digitata L.)pulp flour on sensorial acceptability and nutrient composition of rice cookies. Sci. Afr. 2018, 1, e00002. [CrossRef]

22. Liu, G.; Chen, Y.; He, X.; Yao, F.; Guan, G.; Zhong, B.; Zhou, G. Seasonal changes of mineral nutrients in the fruit of navel orange plants grafted on trifoliate orange and citrange. Sci. Hortic. 2020, 264, 109156. [CrossRef]

23. Salvador-Reyes, R.; Rebellato, A.P.; Lima Pallone, J.A.; Ferrari, R.A.; Clerici, M.T.P.S. Kernel characterization and starch morphology in five varieties of Peruvian Andean maize. Food Res. Int. 2021, 140, 110044. [CrossRef]

24. Yang, B.; Zhang, X.; Zhao, F.; Yang, Y.; Liu, W.; Li, S. Suitability evaluation of different potato cultivars for processing products. Nongye Gongcheng Xuebao/Trans. Chin. Soc. Agric. Eng. 2015, 31, 301-308. [CrossRef]

25. Sood, S.; Khulbe, R.K.; Arun Kumar, A.K.R.; Agrawal, P.K.; Upadhyaya, H.D. Barnyard millet global core collection evaluation in the submontane Himalayan region of India using multivariate analysis. Crop. J. 2015, 3, 517-525. [CrossRef]

26. Lu, F.; Ma, X.; Tan, S.; Chen, L.; Zeng, L.; An, P. Simulative Calibration and Experiment on Main Contact Parameters of Discrete Elements for Rice Bud Seeds. Nongye Jixie Xuebao/Trans. Chin. Soc. Agric. Mach. 2018, 49, 93-99. [CrossRef]

27. Dai, F.; Song, X.; Zhao, W.; Zhang, F.; Ma, H.; Ma, M. Simulative Calibration on Contact Parameters of Discrete Elements for Covering Soil on Whole Plastic Film Mulching on Double Ridges. Nongye Jixie Xuebao/Trans. Chin. Soc. Agric. Mach. 2019, 50, 49-56. [CrossRef]

28. Luo, S.; Yuan, Q.; Gouda, S.; Yang, L. Parameters Calibration of Vermicomposting Nursery Substrate with Discrete Element Method Based on JKR Contact Model. Nongye Jixie Xuebao/Trans. Chin. Soc. Agric. Mach. 2018, 49, 343-350. [CrossRef]

29. Liu, W.; He, J.; Li, H.; Li, X.; Zheng, K.; Wei, Z. Calibration of Simulation Parameters for Potato Minituber Based on EDEM. Nongye Jixie Xuebao/Trans. Chin. Soc. Agric. Mach. 2018, 49, 125-135. [CrossRef]

30. Jones, J.R.; Lawrence, H.G.; Yule, I.J. A statistical comparison of international fertiliser spreader test methods-Confidence in bout width calculations. Powder Technol. 2008, 184, 337-351. [CrossRef]

31. Qiu-ju, W.; Feng, L.; Pan, G.; Zhong-chao, G.; Ben-chao, C.; Yan-xia, L.; Li-li, Z. Effects of Rice Yield and Quality Across Accumulated Temperature Zone Planting in Cold Area. J. Northeast. Agric. Univ. 2015, 22, 1-7. [CrossRef]

32. Wu, P.; Jia, C.; Fan, S.; Sun, Y. Principal component analysis and fuzzy comprehensive evaluation of fruit quality in cultivars of cherry. Nongye Gongcheng Xuebao/Trans. Chin. Soc. Agric. Eng. 2018, 34, 291-300. [CrossRef]

33. Ma, S.; Xu, L.; Yuan, Q.; Niu, C.; Zeng, J.; Chen, C.; Wang, S.; Yuan, X. Calibration of discrete element simulation parameters of grapevine antifreezing soil and its interaction with soil-cleaning components. Nongye Gongcheng Xuebao/Trans. Chin. Soc. Agric. Eng. 2020, 36, 40-49. [CrossRef] 
34. He, X.; Cui, T.; Zhang, D.; Wei, J.; Wang, M.; Yu, Y.; Liu, Q.; Yan, B.; Zhao, D.; Yang, L. Development of an electric-driven control system for a precision planter based on a closed-loop PID algorithm. Comput. Electron. Agric. 2017, 136, 184-192. [CrossRef]

35. Tian, L.; Tang, H.; Wang, J.; Li, S.; Zhou, W.; Yan, D. Design and Experiment of Rebound Dipper Hill-drop Precision Direct Seed-metering Device for Rice. Nongye Jixie Xuebao/Trans. Chin. Soc. Agric. Mach. 2017, 48, 65-72. [CrossRef]

36. Shi, L.; Sun, W.; Zhao, W.; Yang, X.; Feng, B. Parameter determination and validation of discrete element model of seed potato mechanical seeding. Nongye Gongcheng Xuebao/Trans. Chin. Soc. Agric. Eng. 2018, 34, 35-42. [CrossRef]

37. Lü, J.; Feng, X.; Yang, X.; Li, Z.; Zou, F. Design and experiment of supply and suction device on air-suction potato planter. Int. Agric. Eng. J. 2019, 28, 89-100.

38. Liu, Y.; Zong, W.; Ma, L.; Huang, X.; Li, M.; Tang, C. Determination of three-dimensional collision restitution coefficient of oil sunflower grain by high-speed photography. Nongye Gongcheng Xuebao/Trans. Chin. Soc. Agric. Eng. 2020, 36, 44-53. [CrossRef]

39. Aspelmeier, T.; Zippelius, A. Dynamics of a one-dimensional granular gas with a stochastic coefficient of restitution. Phys. Stat. Mech. Appl. 2000, 282, 450-474. [CrossRef]

40. Tang, H.; Wang, J.; Wang, F.; Li, X.; Li, J. Measurement and analysis of rolling friction coefficient of maize seed based on high-speed photography. Int. Agric. Eng. J. 2018, 27, 185-198.

41. Leblicq, T.; Smeets, B.; Ramon, H.; Saeys, W. A discrete element approach for modelling the compression of crop stems. Comput. Electron. Agric. 2016, 123, 80-88. [CrossRef]

42. Hastie, D.B. Experimental measurement of the coefficient of restitution of irregular shaped particles impacting on horizontal surfaces. Chem. Eng. Sci. 2013, 101, 828-836. [CrossRef]

43. Zhan, Z.; Yaoming, L.; Jin, C.; Lizhang, X. Numerical analysis and laboratory testing of seed spacing uniformity performance for vacuum-cylinder precision seeder. Biosyst. Eng. 2010, 106, 344-351. [CrossRef]

44. Xu, D.; Li, W. Effects of no-tillage opening seedbed on maize growth and yield in Northeast China. Int. Agric. Eng. J. 2018, 27, 25-32.

45. Gaitani, N.; Lehmann, C.; Santamouris, M.; Mihalakakou, G.; Patargias, P. Using principal component and cluster analysis in the heating evaluation of the school building sector. Appl. Energy 2010, 87, 2079-2086. [CrossRef]

46. Galhano dos Santos, R.; Bordado, J.C.; Mateus, M.M. Estimation of HHV of lignocellulosic biomass towards hierarchical cluster analysis by Euclidean's distance method. Fuel 2018, 221, 72-77. [CrossRef]

47. Guo, Y.; Lu, X.; Peng, G. Investigation and analysis of the building technology of low temperature germplasm genebanks of China. Nongye Gongcheng Xuebao/Trans. Chin. Soc. Agric. Eng. 2005, 21, 186-190. 